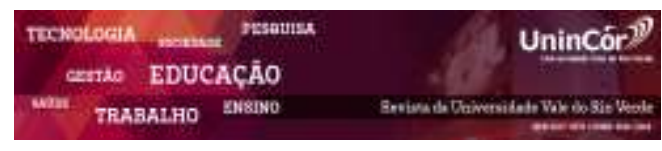

Revista da Universidade Vale do Rio Verde ISSN: 1517-0276 / EISSN: 2236-5362 v. $17 \mid$ n. 1 | Ano 2019

Letícia Rodrigues da Fonseca Universidade Vale do Rio Verde - UninCor leticia.rodrigues.vga@gmail.com

Guilherme Marques Pereira Universidade Vale do Sapucaí - UNIVAS guilherme.marques@bol.com.br

Leandro Costa Fávaro Universidade Vale do Rio Verde - UninCor pedagógico@ead.unincor.edu.br

Daiane Fernandes Pereira Universidade Vale do Rio Verde - UninCor daianepereira@arpariogrande.org..br

Nicole de Santana Gomes Universidade Federal de Lavras - UFLA nicole.gomes@unincor.edu.br

Guilherme Marques Pereira Universidade Vale do Sapucaí - UNIVAS guilherme.marques@bol.com.br

\section{APRENDIZAGEM EXPERIENCIAL: 0 ESTILO DE APRENDIZAGEM DE DOCENTES DE GRADUAÇÃO EM ADMINISTRAÇÃO}

\begin{abstract}
RESUMO
O presente estudo buscou identificar se durante o seu aprendizado o Docente de Graduação em Administração abrange com a mesma ênfase os quatro estágios da Aprendizagem Experiencial, transitando, igualmente, pelos dois eixos, captar e transformar (teoria e prática), pois o educador não poderá ser exclusivamente um teórico e tampouco apenas um prático; deverá haver equilíbrio entre ambos para que a aprendizagem em sala de aula ocorra com efetividade. Para isso, foi realizado um estudo exploratório descritivo, com abordagem quantitativa. Como instrumento de coleta de dados, utilizou-se o Learning Style Inventory - LSI proposto por Kolb (1984). Ao final, constatou-se que os Docentes de Graduação em Administração transitam com um certo equilíbrio pelos dois eixos. Há uma pequena tendência de se priorizar a teoria. Constatou-se ainda, que as educadoras tendem a ser mais práticas e são mais ativas, valorizam a experimentação, participam de realizações e gostam de ver o resultado do trabalho. Ao contrário, os educadores tendem a ser mais teóricos pois gostam de ideias e teorias, além de pensar mais logicamente e serem mais racionais.
\end{abstract}

Palavras-chave: Aprendizagem Experiencial. Estilos de Aprendizagem. Docente.

\section{EXPERIENCIAL LEARNING: THE LEARNING STYLE OF GRADUATION TEACHERS IN ADMINISTRATION}


Keywords: Experiential Learning. Learning Styles. Teacher.

Recebido em: 10/10/2018 - Aprovado em: 10/04/2019 - Disponibilizado em: 15/07/2019

\section{INTRODUÇÃO}

Aprende-se em cada nova situação, independente do ambiente em que estamos inseridos, uma vez que a aprendizagem é uma atividade constante, constituída pelos resultados de nossas tentativas de entender a realidade. No entanto, a sala de aula ainda é um lugar de importantes reflexões e possibilidades de aquisição de conhecimento, devido ao compartilhamento de informações e experiências entre docentes e discentes.

No processo de aprendizagem em sala de aula, o professor é uma importante fonte para aquisição de informação pelo aluno. O educador, ao expor suas experiências e conhecimentos, irá promover a interação entre essas informações e o repertório interno de seus alunos, direcionandoos à aprendizagem (BORDENAVE; PEREIRA, 2004).

Diante deste contexto, as Instituições de Ensino Superior - IESs mostram-se constantemente preocupadas com a qualidade do ensino oferecido, e de maneira específica, com a capacitação de seus professores, pois o conhecimento adquirido pelos alunos no ambiente acadêmico será a base para a sua formação profissional que refletirá a imagem da instituição em que se graduaram.

O professor, além de ter o domínio do conteúdo, precisa ser capaz de fazer uso de práticas pedagógicas que consigam obter resultados satisfatórios no processo de ensino aprendizado (TACHIZAWA; ANDRADE, 2002). Especificamente, deverá favorecer a aquisição e compreensão do conteúdo teórico pelos alunos, bem como, possibilitar a sua aplicação na prática para, posteriormente, promover reflexões sobre os resultados obtidos.

Para Kolb (1984), este cenário é possibilitado pela Aprendizagem Experiencial que permite a intersecção entre a teoria, a prática, as necessidades individuais e as sociais, pois valoriza a interação da vivência do aluno (suas experiências, sensações e repertório) e o meio ambiente (conceitos, experiências dos professores e colegas).

Ainda, de acordo com Kolb (1984), a Aprendizagem Experiencial é composta por quatro estágios: Experiência Concreta; Observação Reflexiva; Conceitualização Abstrata; Experimentação Ativa. Estes estágios situam-se nos eixos basilares da aprendizagem: Captar (aquisição e compreensão da informação) e Transformar (aplicação da informação conforme a realidade do aluno). Ao serem combinados os quatro estágios, estes darão origem a quatro estilos de aprendizagem: Divergente; Assimilador; Convergente; Acomodador. Como um processo, a Aprendizagem Experiencial transita entre os eixos: captar e transformar.

Considerando a teoria da Aprendizagem Experiencial, pressupõe-se que em sua atuação, o professor deverá transitar pelos quatro estágios. 
Deve-se possibilitar a captação da informação no ambiente (Experiência Concreta), para que esta seja analisada e refletida, transformando as ideias anteriores em novas conforme a percepção do aluno (Observação Reflexiva), assim, poderão ser criados esquemas e teorias de acordo com as interpretações sobre a informação adquirida (Conceitualização Abstrata), para que, finalmente, estes sejam aplicados na realidade do educando (Experimentação Ativa). O professor deverá ser capaz de promover a conexão entre os dois eixos da Aprendizagem Experiencial. Não poderá ser exclusivamente um teórico e tampouco apenas um prático; deverá haver equilíbrio, pois transitar somente por um dos eixos não ocasionará o aprendizado efetivo.

Portanto, pretende-se neste estudo, identificar se durante o seu aprendizado o docente de graduação em Administração abrange com a mesma ênfase os quatro estágios da Aprendizagem Experiencial, transitando, igualmente, pelos eixos Captar e Transformar.

Acredita-se, que a forma como o professor se comporta durante o seu aprendizado, o que ele valoriza neste momento, sirva como base para a sua atuação como educador. Assim, ao identificar as deficiências apresentadas por estes docentes na interação com a Aprendizagem Experiencial, será possível obter informações que auxiliem a Gestão de Recursos Humanos da IES no processo de qualificação de seu corpo docente, especificamente no estabelecimento de programas de treinamento que permitam expandir os pontos fortes e reduzir os pontos fracos na ótica dos próprios docentes.

\section{REFERENCIAL TEÓRICO}

\section{O Processo Ensino Aprendizagem}

No processo ensino aprendizagem, o educador lidará com o ser humano, sendo assim, trabalhará constantemente com possibilidades, imprevistos e incertezas. Não poderá obrigar o aluno a aprender. Caberá à ele buscar meios para motivá-lo, propondo desafios que consigam despertar o seu interesse. No entanto, não é sempre que essa tarefa se torna algo fácil para o docente. Para isso, ele deverá fazer uso de estratégias de ensino-aprendizagem que são [...] os meios que o professor utiliza em sala de aula para facilitar a aprendizagem dos alunos, ou seja, para conduzi-los em direção aos objetivos daquela aula, daquele conjunto de aulas ou daquele curso (ABREU; MASSETTO, 1983).

É importante destacar que a metodologia de ensino utilizada pelo docente poderá contribuir consideravelmente na formação da mentalidade dos alunos. O professor, ao expor o conteúdo de sua disciplina, informa, e ao mesmo tempo, forma. As técnicas metodológicas utilizadas na exposição da informação, a forma como esta é disponibilizada irão influenciar na maneira como os alunos irão aprender a aprendêla e em como irão aplicar o conhecimento adquirido, ou que acham que adquiriram (ARANHA, 2000).

Os educandos poderão desenvolver tanto uma mentalidade passiva, recebendo a informação, relacionando o conhecimento como uma cópia fiel do modelo apresentado, como desenvolver uma consciência crítica, procurando respostas aos seus "porquês", procurando dar 
significado ao que foi aprendido (BRITO, 1983; DEMO, 2000).

\section{Aprendizagem Experiencial}

Para a teoria da Aprendizagem Experiencial proposta por David Kolb (1984), o conhecimento é o resultado da transformação de experiências que são captadas pela sensação ou pela conceituação, em uma situação onde essas são vivenciadas, refletidas, significadas e reaplicadas, por meio da reflexão ou da ação, em um processo continuado. Há, primeiramente, uma aquisição da informação, habilidade ou experiência. Esse estímulo externo e o repertório interno do indivíduo interagem e direcionam a aprendizagem para um outro momento, quando há uma especialização do conhecimento. As informações são adaptadas conforme as necessidades e interesses da pessoa, para ocorrer a comparação do novo com o velho, efetivandose a aprendizagem.

A Aprendizagem Experiencial como um processo, transita entre dois eixos captar e transformar. Captar ou prender algo intelectualmente no ato de aprendizagem, é o "aprender". Transformar é internalizar o que se aprendeu, "com-prender". Captar é exercitar a percepção, decodificando as informações externas aproximando-as da sua vivência, juntamente com o repertório armazenado (KOLB, 1984). No processo de transformação, a informação antes isolada ganha um significado através da reflexão e da análise crítica. No ambiente de sala de aula, o eixo Captar refere-se à "aquisição e compreensão da informação" e o
Transformar à "aplicação da informação conforme a realidade do aluno".

Para Kolb (1984) e Berndt e Igari (2005), a Aprendizagem Experiencial, é um ciclo de interações, permitindo que cada nova informação seja experimentada, observada, refletida e conceituada. Portanto, a aprendizagem seria formada por quatro estágios ou fases distintas durante a sua construção:

a) Estágio da Experiência Concreta: neste estágio valoriza-se a relação entre as pessoas nas situações no dia-a-dia. O aprendiz capta a informação nos ambientes sociais nos quais está inserido e centra-se mais em seus sentimentos do que no enfoque sistemático dos problemas. Logo, aprender é o resultado de uma experiência específica vivenciada e do relacionamento com diferentes indivíduos.

b) Estágio da Observação Reflexiva: o aprendiz busca compreender ideias sob diferentes pontos de vista, que surgem à partir de diferentes situações. Confia na objetividade e em seus próprios pensamentos para estabelecer opiniões. Observa e reflete concomitantemente, o que possibilita a transformação de ideias anteriores em novas por meio de mecanismos internos e pessoais.

c) Estágio da Conceitualização Abstrata: neste estágio o resultado da observação reflexiva com a experiência captada, possibilita a criação de esquemas, teorias e interpretações abstratas. $\mathrm{O}$ aprendiz utilizará mais a lógica e se concentrará em estabelecer planificações sistemáticas para desenvolver teorias e ideias para resolver problemas. A ação é baseada na compreensão intelectual de uma situação. Nesta etapa, o 
intelecto capta o novo, exclusivamente por processos mentais.

d) Estágio da Experimentação Ativa: neste estágio os esquemas, teorias e abstrações constituídas a partir das conceituações, são aplicados na realidade do indivíduo com o objetivo de alterá-la ou influenciá-la. Há um interesse em descobrir como teorias e esquemas funcionam na prática de uma situação, em oposição à simples participação, como ocorre no primeiro estágio (Experiência Concreta). O aprendiz sente-se confortável em assumir riscos como aprecia o cumprimento das tarefas e os seus resultados.

Os quatro estágios propostos pelo autor encontram-se nos dois eixos principais da aprendizagem. No eixo "captar" temos a Experiência Concreta com o foco no mundo exterior e a Conceitualização Abstrata com foco no mundo interior da pessoa. No outro eixo, o da “transformação”, temos a Observação Reflexiva que se refere ao mundo interior e a Experimentação Ativa referindo-se ao mundo exterior do sujeito. Segundo Kolb (1984), a aprendizagem se efetiva quando compomos um estágio de um eixo com um estágio de outro eixo, em sequências sucessivas em um permanente círculo que se inicia com a Experiência Concreta, passa pela Observação Reflexiva, para então permitir a Conceitualização Abstrata, encerrando-se o ciclo com a Experimentação Ativa. Para o autor transitar sobre um mesmo eixo, somente captar ou somente transformar, não é considerado possível, não ocorrendo, portanto, o aprendizado.
Combinando-se os estágios, dois a dois, em sequência, teremos de acordo com o autor quatro estilos de aprendizagem:

a) Divergente: caracterizado pela junção entre os estágios Experiência Concreta e Observação Reflexiva. Os indivíduos que possuem o estilo "divergente" observam as situações concretas de diferentes pontos de vista. Tendem a observar mais do que agir. Possuem interesses em diferentes áreas. Sua capacidade imaginativa e sensibilidade aos sentimentos dos outros faz com que estas pessoas direcionem sua atividade profissional para as artes e serviços.

b) Convergente: caracterizado pela junção entre os estágios Conceitualização Abstrata e Experimentação Ativa. As pessoas que possuem o estilo "convergente" buscam identificar o uso prático de uma ideia ou teoria. Possuem uma grande capacidade para resolver problemas e a solução é obtida por meio de processos formais de decisão.

c) Assimilador: caracterizado pela junção entre os estágios Conceitualização Abstrata e Observação Reflexiva. As pessoas que possuem este estilo de aprendizagem são capazes de reunir uma grande variedade de informações para, posteriormente, agrupá-las de modo conciso e lógico para o estabelecimento de esquemas de solução para problemas específicos. O processo de decisão é baseado em modelos reduzidos da realidade.

d) Acomodador: caracterizado pela junção entre os estágios Experiência Concreta e Experimentação Ativa. As pessoas com estilo de aprendizagem "acomodadora" possuem a capacidade de aprender por meio da experiência prática. O aprendiz aplica seus planos e busca 
por experiências novas e desafiadoras, além de se orientarem mais por seus instintos do que por conceitos onde prevalecem as análises lógicas.

No entanto, confiam nas pessoas para se obter informações.

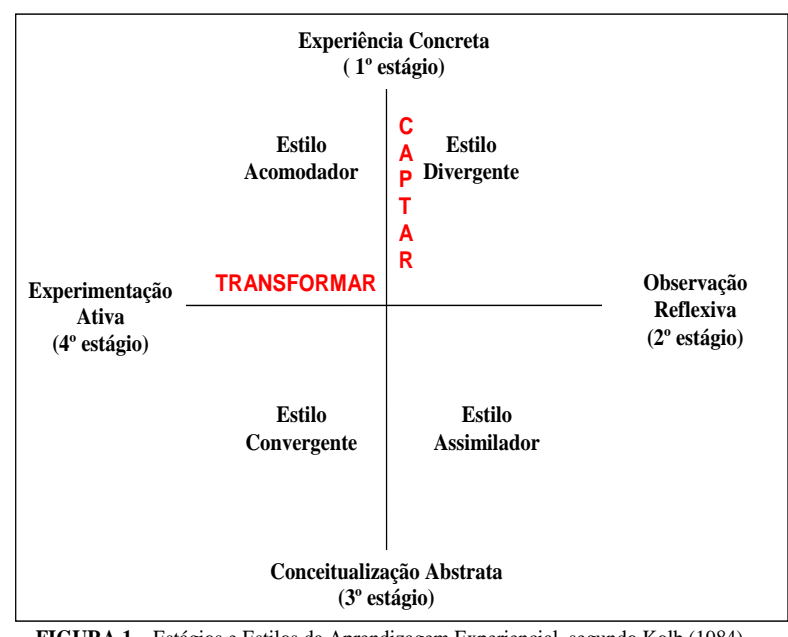

FIGURA 1 - Estágios e Estilos da Aprendizagem Experiencial, segundo Kolb (1984) Fonte: Kolb (1984)

A partir de sua teoria, Kolb (1984), propôs o Learning Style Inventory, o Inventário de Estilos de Aprendizagem que foi projetado para auxiliar o aprendiz a identificar o seu estilo. Os quatro modos de aprendizagem (experiência concreta, observação reflexiva, conceitualização abstrata e experimentação ativa) representam os quatro estágios do processo de aprendizagem.

Assim sendo, o inventário foi planejado para avaliar a importância relativa de cada um desses estágios, a fim de dar indicações de quais modos de aprendizagem o aprendiz costuma enfatizar. Nenhum deles é melhor ou pior que qualquer outro. Mesmo um perfil totalmente equilibrado não é necessariamente o melhor.

Para o autor, a chave para uma aprendizagem eficiente é ser competente em cada modo quando isso for apropriado.

Berndt e Igari (2005), enfatizam ainda que o objetivo da Aprendizagem Experiencial é envolver aprendizes e mestres, motivando-os a aprender, mostrando-lhes como utilizar as habilidades a serem aprendidas para que em novas oportunidades os seus conhecimentos sejam aplicados. Por meio da troca de experiências e informações durante as interações que ocorrem na Aprendizagem Experiencial, obtemos uma aprendizagem cooperativa. $\mathrm{O}$ professor não é visto como o único responsável pelo processo, como o dono do saber. Há a troca de valores, além de educador e educando motivar um ao outro.

\section{METODOLOGIA}

Para atingir o principal objetivo deste estudo, foi realizado um estudo exploratório descritivo com abordagem quantitativa. Segundo Gil (1999), as pesquisas exploratórias têm como principal finalidade desenvolver, esclarecer e modificar conceitos e ideias, tendo em vista, a formulação de problemas mais precisos ou hipóteses pesquisáveis para estudos posteriores. Já, as pesquisas descritivas, visam descrever as características de uma determinada população ou o estabelecimento de relações entre variáveis. Uma de suas características mais significativas está na utilização de procedimentos padronizados de coleta de dados (FACHIN, 2001). Neste estudo, se utilizou como instrumento de coleta de dados o Learning Style Inventory - LSI, proposto por Kolb (1984). Ao preencher o inventário dáse um posto mais alto às palavras que melhor caracterizam a forma pela qual se aprende e um posto mais baixo para aquelas que são menos relacionadas com o estilo de aprendizagem privilegiado. Pode-se achar difícil escolher as palavras que melhor descrevem o estilo, porque não existem respostas certas ou erradas. As diferentes características descritas no inventário 
são igualmente boas. O objetivo do inventário é

descrever como se aprende, e não avaliar as

habilidades de aprendizagem.

Existem nove conjuntos de quatro palavras relacionadas a seguir. Ordene cada conjunto de quatro palavras dando valor quatro para a palavra que melhor caracteriza seu estilo de aprendizagem, três para a próxima palavra que melhor caracteriza seu estilo de aprendizagem, dois para a próxima palavra mais característica e valor um para a palavra que menos caracterize enquanto aprendiz. Certifique-se de que deu um número de ordem diferente para cada uma das quatro palavras de cada conjunto. Não se aceitam empates.

\begin{tabular}{|c|c|c|c|c|}
\hline & Experiência Concreta & Observação Reflevixa & $\begin{array}{c}\text { Conceitualização } \\
\text { Abstrata }\end{array}$ & $\begin{array}{c}\text { Experimentação } \\
\text { Ativa } \\
\end{array}$ \\
\hline 1 & ( ) discriminador & ( ) experimentador & ( ) envolvido & ( ) prático \\
\hline 2 & ( ) receptivo & ( ) relevante & ( ) analítico & ( ) imparcial \\
\hline 3 & ( ) sentimento & ( ) observação & ( ) pensamento & ( ) ação \\
\hline 4 & ( ) aceitador & ( ) assume riscos & ( ) avaliador & ( ) consciente \\
\hline 5 & ( ) intuitivo & ( ) produtivo & ( ) lógico & ( ) questionador \\
\hline 6 & ( ) abstrato & ( ) observador & ( ) concreto & ( ) ativo \\
\hline 7 & $\begin{array}{l}\text { ( ) orientado para o } \\
\text { presente }\end{array}$ & ( ) reflexivo & ( ) orientado para o futuro & ( ) pragmático \\
\hline 8 & ( ) experiência & ( ) observação & ( ) conceitualização & ( ) experimentação \\
\hline 9 & $($ ) intenso & $($ ) reservado & ( ) racional & ( ) responsável \\
\hline & $\mathrm{EC}=\frac{}{234578}$ & $\mathrm{OR}=$ & $\mathrm{CA}=$ & $E A=$ \\
\hline
\end{tabular}

Foram distribuídos aproximadamente 2.000 questionários. Obteve-se ao final 353, tendo sido aproveitados 316. Os entrevistados são docentes de cursos de Graduação em Administração de IESs distribuídos pelo país, principalmente das regiões sudeste, sul e centrooeste.

Utilizou-se uma amostragem por conveniência, pois seria extremamente difícil construir um rol com todos os docentes que

\section{RESULTADOS E DISCUSSÃO}

\section{Perfil do Docente de Graduação em Adminis- tração}

Buscou-se caracterizar o docente de Graduação em Administração, visto que, por pertencer às Ciências Sociais Aplicadas e não às Ciências Tradicionais, a área de Administração não possui um perfil de docente definido, pois atuam em cursos de Graduação em Administração no Brasil

Fez-se uso do software estatístico SPSS para: criação das variáveis; inserção dos dados obtidos pelo instrumento da pesquisa e o de caracterização do entrevistado e para a realização de tratamentos estatísticos.

além de Administradores, atuam como professores profissionais de diversas outras áreas. Assim, obteve-se o seguinte perfil exposto na Tabela 1, conforme o maior percentual apresentado pelas classes das variáveis que compõe o questionário de caracterização do entrevistado: 


\begin{tabular}{|c|c|c|}
\hline $\begin{array}{c}\text { VARIÁVEIS DE } \\
\text { CARACTERIZAÇÃO }\end{array}$ & $\begin{array}{l}\text { PERCENTUAL DA CLASSE } \\
\text { PREDOMINANTE } \\
\end{array}$ & $\begin{array}{c}\text { PERCENTUAL DAS DEMAIS } \\
\text { CLASSES }\end{array}$ \\
\hline Gênero & Masculino $(68,6 \%)$ & Feminino $(31,4 \%)$ \\
\hline Idade & Até 40 anos $(55,0 \%)$ & De 41 anos ou acima $(45,0 \%)$ \\
\hline Tempo de Formado & Até 12 anos $(51,3 \%)$ & De 13 anos ou acima $(48,7 \%)$ \\
\hline Titulação & Até Mestrando $(54,4 \%)$ & Mestre ou acima $(45,6 \%)$ \\
\hline Área da Titulação & Mercadologia;ADM;OSM; $(66,9 \%)$ & Outras $(33,1 \%)$ \\
\hline $\begin{array}{l}\text { Percentual Tempo Dedicado à } \\
\text { Docência }\end{array}$ & Até $50 \%(57,5 \%)$ & De $51 \%$ ou acima $(42,5 \%)$ \\
\hline $\begin{array}{l}\text { Anos Dedicados à Docência de } \\
\text { ADM. }\end{array}$ & Até 5 anos $(54,8 \%)$ & De 6 anos ou acima $(48,4 \%)$ \\
\hline Total Aulas por Semana & Até 16 aulas $(51,6 \%)$ & De 17 aulas ou acima $(48,4 \%)$ \\
\hline Matéria Preferida & RH;Psicologia;Sociologia $(40,1 \%)$ & $\begin{array}{l}\text { Adm. Financeira e Contabilidade } \\
(31,6 \%) \text {; Mercadologia, } \\
\text { Administração e Organização, } \\
\text { Sistema e Métodos }(28,3 \%) .\end{array}$ \\
\hline
\end{tabular}

TABELA 1 - Perfil do Docente de Graduação em Administração

Fonte: Resultados da Pesquisa. Elaborada pelos Autores

\section{Análise dos Quatro Estágios da \\ Os resultados são expostos na Tabela 2:}

Aprendizagem Experiencial

apresentaram médias com valores aproximados.

Buscou-se identificar, na amostra obtida, a

média de respostas dos estágios da

Aprendizagem Experiencial. Constatou-se

equilíbrio entre os estágios, pois ambos

\begin{tabular}{c|c}
\hline Estágios & Média \\
\hline CA (Conceitualização Abstrata) & 8,17 \\
\hline EA (Experimentação Ativa) & 8,12 \\
\hline OR (Observação Reflexiva) & 8,11 \\
\hline EC (Experiência Concreta) & 7,99 \\
\hline
\end{tabular}

TABELA 2 - Média dos Estágios da Aprendizagem Experiencial

Fonte: Resultados da Pesquisa. Elaborada pelos Autores

\section{Associação dos Quatro Estágios da}

\section{Aprendizagem Experiencial com as Variáveis} de Caracterização

Buscou-se, por meio do Teste QuiQuadrado $\left(X^{2}\right)$, verificar se há associação entre as variáveis de caracterização do docente de Graduação em Administração e os quatro estágios da Aprendizagem Experiencial (EC, CA, OR e EA).
De acordo com Berndt (2005), o $X^{2}$ é uma distribuição de valores que compara as estimativas da variância amostral baseadas em infinitas amostras (de tamanho "n"), com o parâmetro real da variância amostral. Este teste serve para, por meio de frequências observadas, comparar se duas variáveis guardam relação entre si ou não. A medida de discrepância entre duas variáveis é denominada $X^{2}$ (Qui-Quadrado). 
A definição desta discrepância é dada pela soma de todas as diferenças entre cada valor observado e o esperado (ao quadrado) em termos relativos ao esperado. $\mathrm{O}$ resultado deste cálculo gera um $X^{2}$ específico para os dados considerados e deverá ser comparado com a distribuição teórica do $X^{2}$.

$\Sigma\left\{(\mathrm{O}-\mathrm{E})^{2} / \mathrm{E}\right\}=$ valor do $X^{2}$ calculado.
Nesta pesquisa, utilizou-se nível de 0,10\% de significância para o teste de hipótese de associação $\left(X^{2}\right)$.

Os resultados obtidos são expostos na Tabela 3 a seguir e descritos posteriormente:

\begin{tabular}{|c|c|c|c|c|c|}
\hline VARIÁVEL & $\mathbf{E C}$ & CA & OR & EA & $\begin{array}{c}\mathbf{N}^{\mathbf{0}} \text { Assoc. Sign } \\
\mathbf{P}<\mathbf{0 , 1}\end{array}$ \\
\hline Gênero & $0,002^{* * *}$ & $0,056^{*}$ & 0,827 & $\begin{array}{c}0,011^{*} \\
*\end{array}$ & 3 \\
\hline Idade & $0,017 * *$ & 0,898 & 0,529 & 0,262 & 1 \\
\hline Titulação & $0,014 * *$ & $0,067 *$ & $0,010 * *$ & 0,241 & 3 \\
\hline Área da Titulação & 0,889 & 0,374 & 0,510 & 0,234 & $\mathbf{0}$ \\
\hline Tempo de Formado & $0,070^{*}$ & 0,921 & 0,385 & $0,067 *$ & 2 \\
\hline $\begin{array}{c}\text { Percentagem de Tempo Dedicado } \\
\text { à Docência }\end{array}$ & $0,025 * *$ & 0,762 & $0,083 *$ & $\begin{array}{c}0,050^{*} \\
*\end{array}$ & 3 \\
\hline $\begin{array}{c}\text { Total Aulas Ministradas por } \\
\text { Semana }\end{array}$ & 0,225 & 0,295 & 0,223 & 0,207 & $\mathbf{0}$ \\
\hline $\begin{array}{c}\text { Anos Dedicados à Docência em } \\
\text { Administração }\end{array}$ & 0,304 & 0,364 & 0,628 & 0,663 & $\mathbf{0}$ \\
\hline Matéria Preferida & 0,565 & 0,278 & 0,787 & 0,174 & $\mathbf{0}$ \\
\hline $\mathrm{N}^{0}$ Assoc. Sign. $\mathbf{P}<0,1$ & 5 & 2 & 2 & $\mathbf{3}$ & \\
\hline
\end{tabular}

TABELA 3 - Resultado do $\left(X^{2}\right)$ - Quatros Estágios da Aprendizagem Experiencial

Legenda: Fonte: Resultados da Pesquisa. Elaborada pelos Autores.

$$
\begin{aligned}
& * *=\mathrm{p}<0,05 \\
& *=\mathrm{p}<0,10
\end{aligned}
$$

De acordo com os resultados obtidos, identificou-se que tendem mais para o estágio EC (Experiência Concreta) professores do gênero feminino, com maior idade, que estão cursando doutorado ou que concluíram, com maior tempo de formado e que possuem maior tempo dedicado à docência, em relação aos do gênero masculino, com menor idade, que estão mestrando, que possuem menor tempo de formado e que dedicam à docência um menor percentual de seu tempo. Tendem mais para o estágio CA (Conceitualizacão Abstrata), docentes do gênero masculino, que estão cursando doutorado ou que concluíram, em relação aos do gênero feminino que estão mestrando.

Tendem mais para o estágio OR (Observação Reflexiva), educadores cursando doutorado ou que concluíram e que dedicam de $31 \%$ a 50\% de seu tempo à docência, em relação aos que possuem titulação de especialista e que dedicam à docência até 30\% de seu tempo.

$$
\text { Tendem mais para o estágio EA }
$$
(Experimentação Ativa), professores do gênero feminino, que possuem maior tempo de formado e que dedicam $71 \%$ ou acima de seu tempo à docência, em relação aos do gênero masculino, 
com menor tempo de formado e que dedicam à docência de $51 \%$ a $70 \%$ de seu tempo.

Analisando estes resultados, observou-se que as mulheres valorizam mais a experiência pois privilegiam os estágios EC (Experiência Concreta) e EA (Experimentação Ativa). Identificou-se ainda, que os professores que dedicam maior percentual de seu tempo à docência, tendem a ser mais práticos do que teóricos, por privilegiarem, igualmente, os estágios EC (Experiência Concreta) e EA (Experimentação Ativa).

\subsection{Análise das Variáveis "Captar" e "Transformar"}

De acordo com as médias apresentadas pelos eixos da Aprendizagem Experiencial, expostas na Tabela 4, sendo "Captar", média do resultado de (EC-CA) e "Transformar", média do resultado de (EA-OR), observou-se que os docentes pesquisados possuem uma ligeira tendência a serem mais teóricos do que práticos. Visto que a diferença é muito pequena, considera-se que há certo equilíbrio entre ambos os eixos.

\begin{tabular}{c|c}
\hline EIXOS & MÉDIA \\
\hline Captar (ec-ca) & $-2,08$ \\
\hline Transformar (ea-or) & 0,16
\end{tabular}

TABELA 4 - Médias dos Eixos da Aprendizagem Experiencial

Fonte: Resultados da Pesquisa. Elaborada pelos Autores

\section{Associação de "Captar" e "Transformar" com as Variáveis de Caracterização}

Igualmente, utilizou-se o Teste QuiQuadrado $\left(X^{2}\right)$ como forma de identificar se há associação entre as variáveis de caracterização do entrevistado com as principais variáveis de estudo, Captar e Transformar. No eixo Captar, temos os estágios: Experiência Concreta (EC) e Conceitualização Abstrata (CA). No Transformar, os estágios: Observação Reflexiva (OR) e Experimentação Ativa (EA). Os resultados são expostos na Tabela 5 a seguir:

\begin{tabular}{|c|c|c|c|}
\hline VARIÁVEL & $\begin{array}{c}\text { EIXO } \\
\text { CAPTAR } \\
\end{array}$ & $\begin{array}{c}\text { EIXO } \\
\text { TRANSFORMAR } \\
\end{array}$ & $\begin{array}{c}\mathrm{N}^{0} \text { Assoc. Sign. } \\
\mathrm{P}<0,1\end{array}$ \\
\hline Gênero & $0,000 * *$ & $0,011 * *$ & 2 \\
\hline Idade & $0,001 * *$ & 0,221 & 1 \\
\hline Titulação & 0,395 & $0,075^{*}$ & 1 \\
\hline Área da Titulação & 0,264 & 0,386 & $\mathbf{0}$ \\
\hline Tempo de Formado & 0,244 & 0,373 & $\mathbf{0}$ \\
\hline 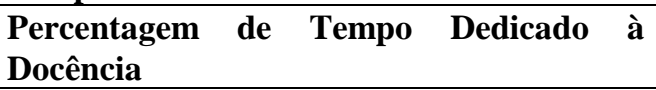 & 0,365 & 0,343 & $\mathbf{0}$ \\
\hline Total Aulas Ministradas por Semana & 0,122 & 0,300 & 1 \\
\hline $\begin{array}{l}\text { Anos Dedicados à } \\
\text { Administração }\end{array}$ & $0,041 * *$ & 0,400 & 1 \\
\hline Matéria Preferida & $0,033 * *$ & 0,510 & $\mathbf{0}$ \\
\hline $\mathrm{N}^{\circ}$ Assoc. Sign. $\mathrm{P}<0,1$ & 3 & 2 & \\
\hline
\end{tabular}

TABELA 5 - Resultado do $\left(X^{2}\right)$ - Eixos Captar e Transformar

Legenda: Fonte: Resultados da Pesquisa. Elaborada pela Autora.

$* *=\mathrm{p}<0,05$ 
$*=\mathrm{p}<0,10$

No eixo Captar, tendem para CA (Conceitualização Abstrata), docentes do gênero masculino, com menor idade, que possuem menor tempo dedicado à docência e que preferem as disciplinas de Administração Financeira e Contabilidade. Já, tendem para EC, os professores do gênero feminino, com maior idade, que possuem maior tempo dedicado à docência e que preferem as disciplinas de Mercadologia, Administração ou OSM.

No eixo Transformar, tendem para OR (Observação Reflexiva), os educadores do gênero masculino com titulação de mestre. Já, tendem para EA, os docentes do gênero feminino com titulação cursando mestrado ou que concluíram.

Os resultados evidenciam que as educadoras tendem mais para a experiência e os educadores mais para a teoria, confirmando as informações obtidas no teste de hipótese de associação dos estágios da Aprendizagem Experiencial em que as educadoras apresentaram maior tendência para os estágios (EC e EA).

Confirmou-se, igualmente, os resultados obtidos pelo teste de correlação, que expôs que as educadoras valorizam mais os estágios EC e EA, privilegiando o estilo “Acomodador".

Observou-se ainda, no teste de hipótese de associação dos eixos da Aprendizagem Experiencial, que os docentes com menor idade focalizam mais o mundo interior por privilegiarem o estágio (CA) e os com maior idade o mundo exterior por privilegiarem o estágio (EC).

\section{CONCLUSÃO}

Considerando o principal objetivo deste estudo, obtiveram-se importantes informações a respeito do docente de graduação em Administração e sua interação com a Aprendizagem Experiencial. Quanto ao perfil do docente, verificou-se que esse educador é do gênero masculino, com idade até 40 anos. Possui até 12 anos de formado, seu grau máximo de titulação é cursando mestrado. A área de sua titulação é Mercadologia, Administração ou OSM, dedicando à docência até $50 \%$ de seu tempo, tendo dedicado para a docência de Administração até 5 anos. Ministra, no semestre, até 16 aulas semanais e possui como matérias preferidas: RH, Psicologia ou Sociologia. Constatou-se que as educadoras tendem a ser mais práticas, são mais ativas, valorizam a experimentação, participam de realizações e gostam de ver o resultado do trabalho. Os estágios que abrangem com maior ênfase são: EC (Experiência Concreta) e EA (Experimentação Ativa). Ao contrário, os educadores de Administração tendem a ser mais teóricos, pois gostam de ideias e teorias, além de pensar mais logicamente e serem mais racionais. Os estágios que abrangem com maior ênfase são: CA (Conceitualização Abstrata) e OR (Observação Reflexiva). O mesmo foi comprovado no teste de correlação em que as mulheres valorizariam os estágios EA e EC, privilegiando o estilo "Acomodador", e os homens os estágios CA e OR, privilegiando o estilo "Assimilador".

Constatou-se também, que os professores que dedicam maior percentual de seu tempo à 
docência, tendem a ser mais práticos do que teóricos e que os docentes com menor idade focalizam mais o mundo interior, ou seja, buscam constantemente captar e entender o novo. Já, os com maior idade, privilegiam o mundo exterior, pois sentem-se mais a vontade em assumir riscos.

Encontrou-se durante a pesquisa algumas limitações. Quanto ao questionário utilizado, alguns entrevistados não responderam ou fizeram de forma incompleta.

Para pesquisas futuras, almeja-se adentrar um pouco mais na questão dos estilos de aprendizagem, buscando identificar a proporção de docentes que privilegiam cada um dos quatro estilos. É preciso ainda que esta pesquisa seja replicada com o objetivo de validar os dados obtidos e/ou complementá-los com novos achados.

\section{REFERÊNCIAS}

ABREU, Maria C.; MASETTO, Marcos T. O professor universitário em aula : prática e princípios teóricos. São Paulo : MG Ed. Associados, 1983.

ARANHA, M. L. Filosofia da educação. São Paulo : Moderna, 2000.

BERNDT, Alexander; IGARI, Camila O. Um teste com a proposta brasileira para o "Inventário de Estilos de Aprendizagem de Kolb", em VIII Semead - Seminários em Administração FEA-USP, São Paulo, 2005.

BERNDT, Alexander. Apostila da disciplina de métodos e técnicas de pesquisa em administração. (Mestrado em Administração). CNEC - Campanha Nacional de Escolas da Comunidade. 2005.

BORDENAVE, Juan D.; PEREIRA, Adair M.

Estratégias de ensino aprendizagem. Rio de Janeiro: Editora Vozes, 2004.

BRITO, Sulami P. Psicologia da aprendizagem centrada no estudante. Campinas : Papirus, 1983.
DEMO, Pedro. Conhecer \& aprender : sabedoria dos limites e desafios. Porto Alegre : Editora Artes Médicas Sul, 2000.

GIL, A.C. Métodos e Técnicas de Pesquisa Social. 5

ed. São Paulo : Atlas, 1999.

FACHIN, Odília. Fundamentos da metodologia. São Paulo : Saraiva, 2001.

KOLB, David A. Experiential learning. New Jersey : Ed. O’Doughert, 1984.

TACHIZAWA, Takeshy; ANDRADE, Rui Otávio Bernardes. Gestão de instituições de ensino. Rio de Janeiro: Editora FGV, 2002.

Letícia Rodrigues da Fonseca

Doutora pela Universidade Presbiteriana Mackenzie.

Guilherme Marques Pereira

Doutor em Ciências da Linguagem pela Universidade Vale do Sapucaí - UNIVÁS

Leandro Costa Fávaro

Mestre em Sustentabilidade em Recursos Hídricos pela Universidade Vale do Rio Verde - UninCor

Daiane Fernandes Pereira

Mestranda em Sustentabilidade em Recursos Hídricos pela Universidade Vale do Rio Verde UninCor

Nicole de Santana Gomes
Mestra em Educação pela Universidade Federal de
Lavras - UninCor

